\title{
Facile Synthesis and Study of Microporous CANAL-Tröger's Base Ladder Polymers for Membrane Air Separation
}

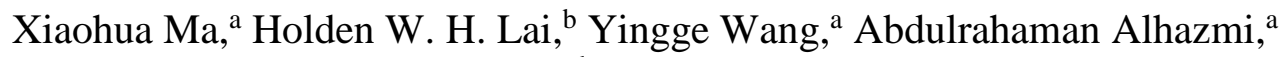 \\ Yan Xia, ${ }^{\text {b* }}$ Ingo Pinnau ${ }^{\text {a* }}$
}

\begin{abstract}
${ }^{a}$ Functional Polymer Membranes Group, Advanced Membranes and Porous Materials Center, Division of Physical Science and Engineering, Chemical Engineering Program, King Abdullah University of Science and Technology (KAUST), Thuwal 23955-6900, KSA.

${ }^{\mathrm{b}}$ Department of Chemistry, Stanford University, Stanford, California 94305, United States.
\end{abstract}

Corresponding authors:

a* E-mail: ingo.pinnau@kaust.edu.sa;

b* E-mail: yanx@ stanford.edu

Keywords: ladder polymer, microporosity, Tröger's base, gas separation membranes 


\begin{abstract}
We report the facile synthesis and study of two soluble microporous ladder polymers, CANALTBs, by combining catalytic norbornene-arene annulation (CANAL) and Tröger's Base (TB) formation. The polymers were synthesized in two steps from commercially available chemicals in high yields. CANAL-TBs easily formed mechanically robust films. CANAL-TBs were thermally stable up to $440{ }^{\circ} \mathrm{C}$ and exhibited very high Brunauer-Teller-Emmett surface areas of 900-1000 $\mathrm{m}^{2} \mathrm{~g}^{-1}$. The gas separation performance of the CANAL-TBs for the $\mathrm{O}_{2} / \mathrm{N}_{2}$ pair is located between the 2008 and 2015 permeability/selectivity upper bounds. After 300 days of aging, CANAL-TBs still exhibited $\mathrm{O}_{2}$ permeability of 200-500 barrer with $\mathrm{O}_{2} / \mathrm{N}_{2}$ selectivity of about 5 . The polymer with more methyl substituents exhibited higher permeability and slightly larger intersegmental spacing as revealed by WAXS, presumably due to more frustrated chain packing. The facile synthesis, excellent mechanical properties, and promising air separation performance of the CANAL-TB polymers make them attractive membrane materials for various air separation applications, such as aircraft on-board nitrogen generation and oxygen enrichment for combustion.
\end{abstract}


Solution-processible ladder polymers of intrinsic microporosity (PIMs) are an emerging class of membrane gas separation materials. ${ }^{1-7}$ Rigid and contorted ladder motifs in the polymer backbone are key to induce frustrated polymer chain packing, leading to high fractional free volume and microporosity in polymers. The gas separation properties of PIMs depend strongly on the molecular structures and micropore size distributions..$^{8-11}$ To develop highly permeable and selective polymer membranes, it is essential to have both ultramicropores $(<7 \AA)$ for highly selective gas transport and larger interconnected micropores ( $>10 \AA$ ) for fast gas permeation. This general concept resulted in systematic development of various PIMs with very high permeability and generally moderate selectivity for several important gas pairs, ${ }^{8,12-18}$ including $\mathrm{O}_{2} / \mathrm{N}_{2}, \mathrm{H}_{2} / \mathrm{N}_{2}, \mathrm{H}_{2} / \mathrm{CH}_{4}$ and, more recently, pure-gas $\mathrm{CO}_{2} / \mathrm{N}_{2}$ and $\mathrm{CO}_{2} / \mathrm{CH}_{4}$, redefining upper bounds in the separation performance. ${ }^{19-20}$

PIMs were first developed based on polycondensation of tetrafluoroterephthalonitrile with contorted biscatechol motifs based on most commonly spirobisindane (SBI), spirobifluorene (SBF), and triptycene. ${ }^{8,13,21-22}$ In 2013, the McKeown group reported using Tröger's base (TB) formation as a method to synthesize ladder PIMs (TB-PIMs) via reaction of ladder or spirocyclic aryl diamines with dimethoxymethane in acid. ${ }^{14-15,23-25}$ The TB linkage consists of a rigid, bent, and chiral methanodibenzodiazocine structure. TB motifs have also been used as building blocks to synthesize pseudo-ladder PIM polyimides (PIM-PIs), which displayed excellent gas separation performance. ${ }^{26-31}$ The biscatechol condensation and TB formation have been the dominating methods for the synthesis of microporous ladder polymers. The Xia group recently reported an efficient catalytic arene-norbornene annulation (CANAL) polymerization to synthesize rigid hydrocarbon ladder polymers using aryl bromides and norbornadiene as the monomers. ${ }^{32-36}$ CANAL polymerization yields rigid and contorted norbornyl benzocyclobutene ladder backbones that result in high surface areas and microporosity. The CANAL ladder polymers from simple dibromobenzenes and norbornadiene give ribbon-like rigid chain conformations. CANAL polymer films exhibited high gas permeability but low selectivity. ${ }^{36}$ Interestingly, even simple short aliphatic substituents were found to significantly affect the permeability without affecting the selectivity. ${ }^{36} \mathrm{We}$ became interested in modifying the backbone of CANAL polymers and investigating its effect on gas separation performance.

We now report a series of ladder polymers, CANAL-TBs, fusing CANAL and TB motifs. Their synthesis was facile and high-yielding, requiring only two steps from commercially available starting materials. These CANAL-TB polymers easily formed films with excellent mechanical properties, and exhibited significantly improved $\mathrm{O}_{2} / \mathrm{N}_{2}$ selectivity to $\sim 5$ without reduction in $\mathrm{O}_{2}$ permeability compared to the recently reported pure CANAL hydrocarbon 
polymers. ${ }^{36}$ The facile synthesis, robust mechanical properties, and excellent air separation performance make the CANAL-TB polymers promising membrane materials for air separation applications.

We chose two commercially available $p$-bromoanilines and norbornadiene to synthesize two norbornyl bis(aminobenzocyclobutene) ladder aryl diamines, $\mathbf{1}$ and $\mathbf{2}$, with two and four methyl substituents, respectively (Scheme 1). CANAL reaction using $2 \mathrm{~mol} \% \mathrm{Pd}(\mathrm{OAc})_{2}, 4$ mol\% $\mathrm{PPh}_{3}$, and 1 eq. $\mathrm{Cs}_{2} \mathrm{CO}_{3}$ in 1,4-dioxane at $150{ }^{\circ} \mathrm{C}$ proceeded smoothly to give $\mathbf{1}$ and $\mathbf{2}$ in $80 \%$ yield. The ortho-methyl group on bromoanilines was important to achieve high yield and selectivity in CANAL. Because of the exclusive exo-selectivity of CANAL, these CANAL diamines exhibited a "W" shape (existing in syn and anti-diamine isomers). The diamines $\mathbf{1}$ and 2 were then polymerized via TB formation ${ }^{14,23}$ by reacting with dimethoxymethane in neat $\mathrm{CF}_{3} \mathrm{COOH}$ to produce CANAL-TB-1 and CANAL-TB-2, respectively. The resulting polymers were soluble in dichloromethane and chloroform.

\section{Scheme 1. Synthetic Routes of the CANAL-TB Ladder Polymers.}

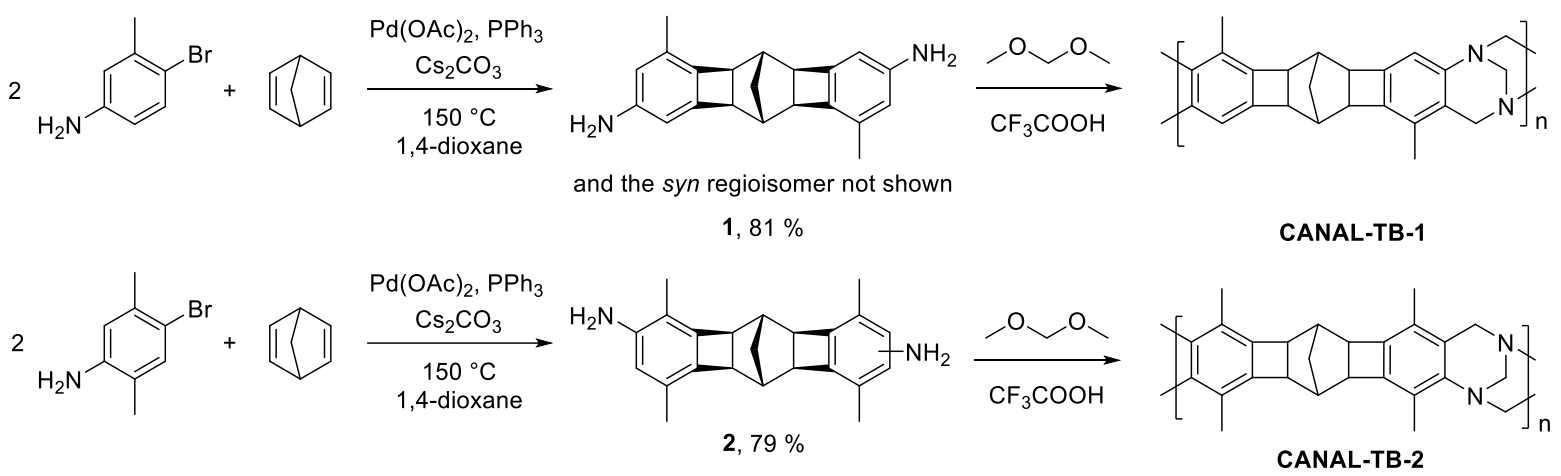

${ }^{1} \mathrm{H}$ NMR spectroscopy of the isolated polymers showed complete preservation of all the expected signals from the CANAL motif (Figure S1), especially the characteristic signal from benzocyclobutene around $3.1 \mathrm{ppm}$, suggesting its stability under the strongly acidic conditions for TB formation. New signals around 3.7-4.8 ppm corresponding to the TB linkages also appeared. For CANAL-TB-2, no aromatic proton signals were observed as expected, whereas for CANAL-TB-2, one peak at 6.7 ppm was observed. Integrations of all these peaks yielded ratios consistent with those expected for the proposed TB ladder backbone. FT-IR spectroscopy of the polymers showed the disappearance of N-H stretch peaks at $3000-3500 \mathrm{~cm}^{-1}$, which were strong in the CANAL diamines (Figure S2).

Because CANAL-TB-1 has two possible aromatic sites for TB formation, we carried out a TB model reaction using singly fused ladder compound $\mathbf{3}$ to probe the regioselectivity in TB 
formation for CANAL-TB-1 (Scheme 2). The regiochemistry of the products was determined by $1-\mathrm{D}{ }^{1} \mathrm{H}$ nuclear Overhauser effect (NOE) experiments, by saturating the methyl frequencies. For the linear fusion, where the TB formation occurs at the 2 position, NOE correlation is expected between the benzylic protons $\mathrm{H}_{\mathrm{a}}$ and the methylene protons $\mathrm{H}_{\mathrm{b}}$ in TB; whereas in the angular fusion, where the TB formation occurs at the 6 position, NOE correlation is expected between the benzylic protons $\mathrm{H}_{\mathrm{c}}$ and the aromatic proton $\mathrm{H}_{\mathrm{d}}$ (Scheme 2). Using this NOE method, of the three potential regioisomers $\mathbf{4 a - c}$, we only identified $\mathbf{4 a}$ and $\mathbf{4 c}$ at a 1:9 ratio (Figure S3-7). Because 4a contains one linear and one angular fusion and both fusions in $\mathbf{4 c}$ are linear, the result of this model reaction suggests that the ratio of angular vs linear fusion in the backbone of CANAL-TB-1 may be 1:19. Therefore, CANAL-TB-1 and CANAL-TB-2 may be expected to have similarly extended backbone conformations.

Scheme 2. Model Reaction to Assess the Regio-Selectivity of the TB Formation.

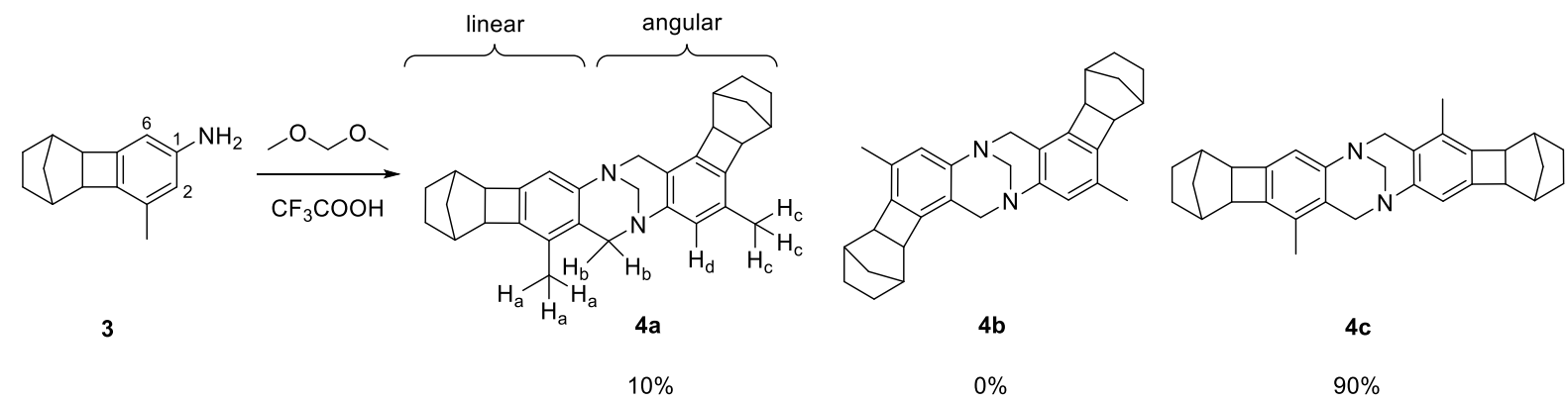

In this study, isotropic films with thicknesses of $\sim 40$ um were easily obtained by casting from CANAL-TBs' chloroform solutions. The films exhibited excellent mechanical properties, still maintaining their structural integrity after repeated sharp bending and twisting (Figure 1). We measured the ultimate tensile strength of CANAL-TB-1 and CANAL-TB-2 to be 63 and 46 $\mathrm{MPa}$, respectively, similar to that of widely investigated PIMs-PIM-1 (30-50 MPa $)^{37-39}$ and PIM-TRIP-TB (45 MPa). ${ }^{15}$ The films were also remarkably flexible with high elongation at break of 15 and $28 \%$ for CANAL-TB-1 and CANAL-TB-2, respectively (Figure S8, Table S1). The Young's modulus was determined to be 1.6 and 0.42 GPa for CANAL-TB-1 and CANALTB-2, respectively, which is comparable to the stiffness of PIM-1 and PIM-TRIP-TB (Table $\mathrm{S} 1)$. 


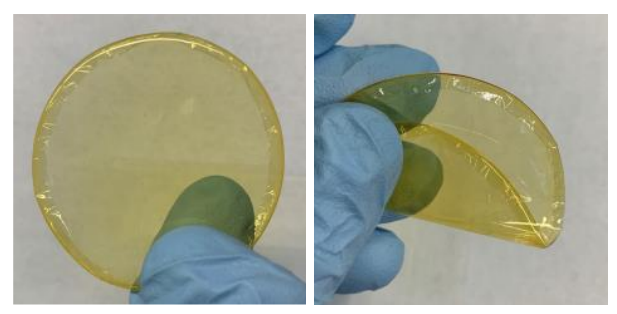

Figure 1. Photos of CANAL-TB films demonstrating its mechanical flexibility.

Both CANAL-TB polymers exhibited very high thermal stability with the onset of thermal decomposition at $5 \%$ mass loss $\left(\mathrm{T}_{\mathrm{d}}, 5 \%\right)$ around $440{ }^{\circ} \mathrm{C}$ (Figure $\mathrm{S} 9$ ), and high carbonization yields of 74 and $69 \%$ for CANAL-TB-1 and CANAL-TB-2, respectively, at $800{ }^{\circ} \mathrm{C}$.

We investigated the BET surface areas and microporosity of the CANAL-TB polymers by $\mathrm{N}_{2}$ sorption at $77 \mathrm{~K}$ up to 1 bar. Both polymers exhibited Type II sorption isotherms and abundant microporosity with large nitrogen uptake at low pressure $\left(\mathrm{p} / \mathrm{p}_{0}<0.05\right)$ (Figure $\left.2 \mathrm{a}\right)$. CANAL-TB-1 and CANAL-TB-2 showed high BET surface areas of 881 and $987 \mathrm{~m}^{2} \mathrm{~g}^{-1}$, respectively (Table 1), which are comparable to the highest reported surface areas from soluble PIMs, such as PIM-Trip-TB $\left(899 \mathrm{~m}^{2} \mathrm{~g}^{-1}\right),{ }^{15}$ PIM-BTrip-TB $\left(870 \mathrm{~m}^{2} \mathrm{~g}^{-1}\right),{ }^{24}$ PIM-EA-TB (1028 $\left.\mathrm{m}^{2} \mathrm{~g}^{-1}\right),{ }^{23}$ PIM-TMN-Trip $\left(1050 \mathrm{~m}^{2} \mathrm{~g}^{-1}\right),{ }^{16}$ and PIM-TMN-SBI $\left(1015 \mathrm{~m}^{2} \mathrm{~g}^{-1}\right) .{ }^{16}$ The higher BET surface area for CANAL-TB-2 compared to that of CANAL-TB-1 may be attributed to the more frustrated chain packing imposed by two additional methyl substituents. We derived the pore size distributions from $\mathrm{N}_{2}$ sorption isotherms by non-local density functional theory (NLDFT) using the standard slit carbon model (Figure $2 \mathrm{~b}$ )..$^{40}$ Both polymers exhibited abundant micropores with pore width in the range of $\sim 11$ to $15 \AA$ and ultramicropores $<7 \AA$. The ultramicropore distributions appeared very similar between the two polymers, despite their different gas permeation properties as discussed below. The difference in gas permeation between the two polymers may result from structural differences in pore size $(<5 \AA)$ that are too small for $\mathrm{N}_{2}$ to access at $77 \mathrm{~K}$ in the $\mathrm{N}_{2}$ sorption measurement. 

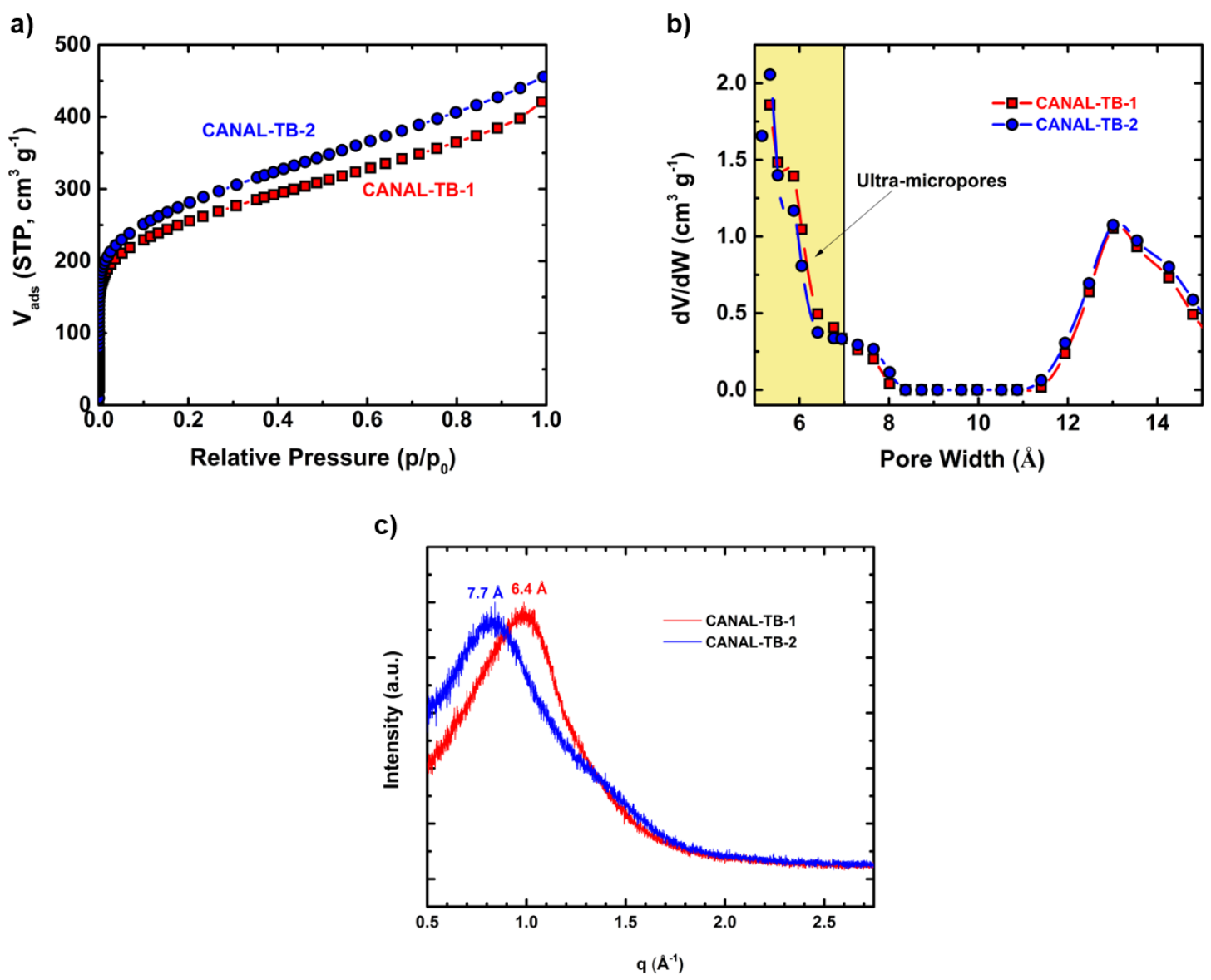

Figure 2. Characterization of microporosity of CANAL-TB polymers. a) $\mathrm{N}_{2}$ sorption isotherms of CANAL-TB-1 and CANAL-TB-2 at $77 \mathrm{~K}$; b) pore size distribution of CANAL-TB-1 and CANAL-TB-2 derived from $\mathrm{N}_{2}$ adsorption isotherms by non-local density functional theory using the standard slit carbon model $;^{40}$ c) wide-angle X-ray scattering of CANAL-TB-1 and CANAL-TB-2 films. Both films were soaked in methanol and then dried in a vacuum oven at $120{ }^{\circ} \mathrm{C}$ for $24 \mathrm{~h}$.

Wide-angle X-ray scattering of the two polymer films indicated their amorphous structures and revealed the difference in their intersegmental spacing (Figure 2c). CANAL-TB-1 displayed a broad peak with maximum intensity at $\mathrm{q}=1.0 \AA^{-1}$, corresponding to $6.4 \AA$. CANALTB-2 displayed a broad peak shifted toward lower q with a larger $d$-spacing of $7.7 \AA$, indicating its larger intersegmental spacing, which again may be attributed to its additional methyl substituents.

We next evaluated the gas permeation properties of CANAL-TB-1 and CANAL-TB-2 films for $\mathrm{H}_{2}, \mathrm{~N}_{2}, \mathrm{O}_{2}, \mathrm{CH}_{4}$, and $\mathrm{CO}_{2}$ at 2 bar upstream pressure and $35^{\circ} \mathrm{C}$ using the constant volume/variable pressure method (Table 1). Previously reported TB-containing ladder PIMs, PIM-TRIP-TB, PIM-EA-TB, and PIM-MP-TB, are included in Table 1 for comparison. 
Table 1. Gas Permeability and Gas-Pair Selectivity of CANAL-TB-1 and CANAL-TB-2 ( $\mathrm{T}=35^{\circ} \mathrm{C} ; \mathrm{p}=2$ bar) and Related Tröger's Base-Containing PIMs.

\begin{tabular}{|c|c|c|c|c|c|c|c|c|c|}
\hline \multirow{2}{*}{$\begin{array}{l}\text { Polymer } \\
\text { (thickness in } \mu \mathrm{m} \text { ) }\end{array}$} & \multicolumn{5}{|c|}{ Permeability (barrer) } & \multicolumn{4}{|c|}{ Ideal selectivity (-) } \\
\hline & $\mathrm{H}_{2}$ & $\mathrm{~N}_{2}$ & $\mathrm{O}_{2}$ & $\mathrm{CH}_{4}$ & $\mathrm{CO}_{2}$ & $\mathrm{H}_{2} / \mathrm{N}_{2}$ & $\mathrm{H}_{2} / \mathrm{CH}_{4}$ & $\mathrm{O}_{2} / \mathrm{N}_{2}$ & $\mathrm{CO}_{2} / \mathrm{CH}_{4}$ \\
\hline CANAL-TB- $1^{a}$ & 2760 & 97 & 463 & 121 & 1678 & 28.5 & 22.8 & 4.8 & 13.9 \\
\hline Aged 300 d $(39 \mu \mathrm{m})$ & 1163 & 39 & 204 & 53 & 749 & 29.8 & 22.0 & 5.2 & 14.1 \\
\hline CANAL-TB- $2^{a}$ & 3608 & 162 & 747 & 205 & 2520 & 22.3 & 17.6 & 4.6 & 12.3 \\
\hline Aged $300 \mathrm{~d}(39 \mu \mathrm{m})$ & 2452 & 110 & 528 & 129 & 1751 & 22.4 & 19.1 & 4.8 & 13.6 \\
\hline PIM-TRIP-TB ${ }^{b, c}$ & 8039 & 629 & 2718 & 905 & 9709 & 12.8 & 8.9 & 4.3 & 10.7 \\
\hline Aged $100 \mathrm{~d}(132 \mu \mathrm{m})$ & 4740 & 189 & 1073 & 218 & 3951 & 25.0 & 21.7 & 5.7 & 18.1 \\
\hline $\begin{array}{l}\text { PIM-EA-TB } \\
(181 \mu \mathrm{m})^{b, d}\end{array}$ & 7760 & 525 & 2150 & 699 & 7140 & 14.8 & 11.1 & 4.1 & 10.2 \\
\hline $\begin{array}{l}\text { PIM-MP-TB } \\
(94 \mu \mathrm{m})^{b, e}\end{array}$ & 4050 & 200 & 999 & 264 & 3500 & 20.3 & 15.3 & 5.0 & 13.3 \\
\hline $\begin{array}{l}{ }^{a} \text { Soaked in methanol } \\
\text { then air dried; tested }\end{array}$ & then & ied & 120 & & vacu & for 24 & $\begin{array}{l}4 \text { h. }{ }^{b} \text { So } \\
25 .\end{array}$ & in & hanol and \\
\hline
\end{tabular}

The order of gas permeabilities for both CANAL-TB-1 and CANAL-TB-2 was $\mathrm{PH}_{2}>\mathrm{PCO}_{2}>$ $\mathrm{PO}_{2}>\mathrm{PCH}_{4}>\mathrm{PN}_{2}$, which is consistent with those of other reported TB-containing PIM films, such as PIM-EA-TB, ${ }^{14}$ PIM-MP-TB,${ }^{25}$ and aged PIM-Trip-TB.${ }^{15}$ Freshly prepared CANALTB-1 and CANAL-TB-2 films exhibited $\mathrm{O}_{2}$ permeability of 463 and 747 barrer and an $\mathrm{O}_{2} / \mathrm{N}_{2}$ selectivity of 4.8 and 4.6, respectively. Highly microporous PIM films commonly experience physical aging with significantly reduced gas permeability over time and often an increase in selectivity. ${ }^{6,11}$ Therefore, we studied the gas permeation for CANAL-TB-1 and CANAL-TB-2 films that were aged at room temperature. After 300 days of physical aging, both films still showed promising performance for air separation applications with $\mathrm{O}_{2}$ permeability of 204 and 528 barrer for CANAL-TB-1 and CANAL-TB-2, respectively. Interestingly, the percentage decrease in $\mathrm{O}_{2}$ permeability was smaller for the more permeable CANAL-TB-2 (29\% decrease from the freshly prepared film) than for CANAL-TB-1 (56\% decrease from the freshly prepared film). Aging also resulted in moderate increases in selectivity for all gas pairs listed in Table 1. This behavior is different from what was previously observed in the aging of other PIMs, which showed significant boosts in selectivity and significant reduction in permeability, as shown for PIM-TRIP-TB (Table 1). ${ }^{6,11,41}$ We hypothesize that the reduction in gas permeability upon aging without significant increase in selectivity for CANAL-TB films may be due to the 
collapse of larger micropores $(>10 \AA)$ without generation of size-selective ultramicropores $(<7$ $\AA$ ). Nevertheless, the performance after long-term aging (Table 1), $\mathrm{O}_{2} / \mathrm{N}_{2}$ selectivity of 5.2 and 4.8 for CANAL-TB-1 and CANAL-TB-2, respectively, remained attractive for air separation application, including membrane production of oxygen-enriched air for combustion and nitrogen generation from air for fuel tank inerting on aircrafts, where materials with high $\mathrm{O}_{2}$ permeability and moderate $\mathrm{O}_{2} / \mathrm{N}_{2}$ selectivity are desirable to provide compact and lightweight systems. ${ }^{3,42}$

To investigate details of physical aging, we determined diffusion coefficients for fresh and 300-day old samples using the time-lag method. ${ }^{43}$ Table S2 shows the diffusion coefficients for $\mathrm{N}_{2}, \mathrm{O}_{2}, \mathrm{CH}_{4}$, and $\mathrm{CO}_{2}$ as well as the diffusion selectivity and solubility selectivity for $\mathrm{O}_{2} / \mathrm{N}_{2}$ and $\mathrm{CO}_{2} / \mathrm{CH}_{4}$ in CANAL-TB films on day 1 and after 300 days. Clearly, aged samples showed significant drop in diffusion coefficients, accompanied by only marginal increase in diffusion selectivity $\left(\alpha_{D}\right)$ for $\mathrm{O}_{2} / \mathrm{N}_{2}$ and $\mathrm{CO}_{2} / \mathrm{CH}_{4}$. On the other hand, physical aging had essentially no effect on $\mathrm{O}_{2} / \mathrm{N}_{2}$ solubility selectivity, which remained around 1.1 .

The $\mathrm{O}_{2} / \mathrm{N}_{2}$ gas separation performance of CANAL-TB-1 and CANAL-TB-2 is compared to the seminal PIM-1, several other TB-based PIMs, and three commercial membranes used for air separations-Matrimid, polysulfone (PSF), and poly(phenylene oxide) (PPO) (Figure 3). All current commercial membranes have very low permeability and fall below the 1991 upper bound for $\mathrm{O}_{2} / \mathrm{N}_{2}$ separation. ${ }^{44}$ Since the advent of PIMs, significantly more permeable membrane polymers have been reported, moving up the tradeoff curves to the 2008 and 2015 records. ${ }^{19,45}$ Like other TB-containing PIMs, the performance of CANAL-TB-1 and CANALTB-2 is located between the 2008 and 2015 upper bounds for $\mathrm{O}_{2} / \mathrm{N}_{2}$ separation, but CANALTBs exhibit higher selectivity and lower permeability compared to several other TB-containing PIMs (Figure 3). Notably, the $\mathrm{O}_{2}$ permeability of CANAL-TBs is still very high. Their performance makes them desired membrane materials for air separation applications that require high $\mathrm{O}_{2}$ permeability (> 500 barrer) and only moderate $\mathrm{O}_{2} / \mathrm{N}_{2}$ selectivity ( 4-5), such as combustion and fuel tank inerting applications. Their simple two-step high-yielding synthesis from commercial chemicals and excellent mechanical properties of the films are two additional important features that make CANAL-TBs promising membrane polymers for air separations. 


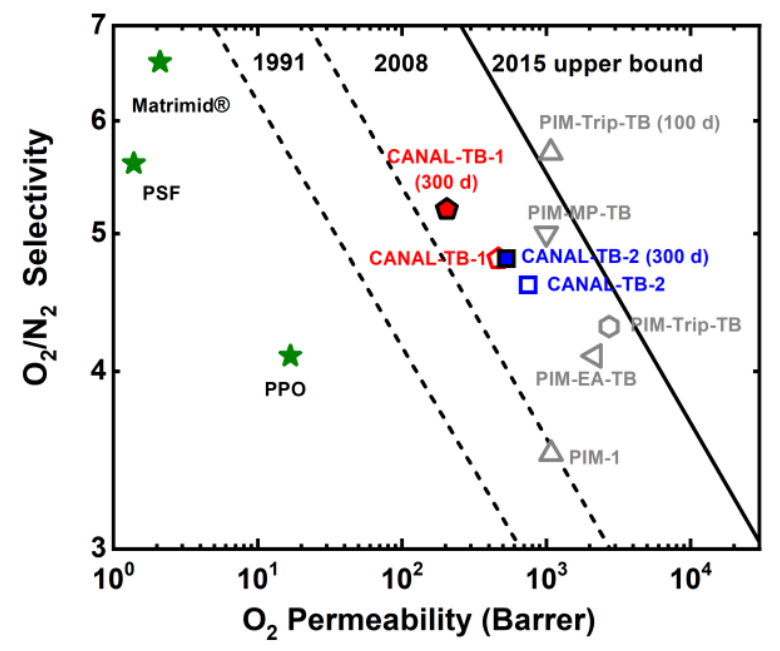

Figure 3. $\mathrm{O}_{2} / \mathrm{N}_{2}$ separation performance of CANAL-TB-1 and CANAL-TB-2 (open symbols: freshly prepared; closed symbols: aged for 300 days) and previously reported ladder-type PIMs relative to $1991^{44}$ (dashed line), $2008^{45}$ (dashed line), and $2015^{19}$ (solid line) upper bounds.

In summary, we report two microporous ladder polymers, CANAL-TB-1 and CANAL-TB2, with backbones consisting of two rigid ladder motifs, fused norbornyl benzocyclobutene and Tröger's base. Their synthesis from commercially available bromoanilines and norbornadiene was simple and high yielding. CANAL-TBs exhibited excellent thermal stability, robust mechanical properties, and high gas permeability. CANAL-TB-2 with more methyl substituents exhibited a more open internal structure than CANAL-TB-1, as suggested by its larger average intersegmental spacing and higher gas permeability. Films of these polymers showed promising air separation performance. After 300 days of aging, CANAL-TB-1 and CANAL-TB-2 still displayed high $\mathrm{O}_{2}$ permeability and moderate $\mathrm{O}_{2} / \mathrm{N}_{2}$ selectivity. The encouraging separation performance, facile synthesis, thermal and chemical stability, and remarkable mechanical properties collectively make these polymers excellent candidates to be further developed into thin-film composite membranes for air separation applications.

\section{ASSOCIATED CONTENT}

\section{Supporting Information}

Experimental details, NMR and FT-IR spectra, analysis of model reaction, mechanical properties, gas diffusion coefficients, permeability/selectivity trade-offs, 3D MD simulations and FFV of CANAL-TBs. The Supporting Information is available free of charge on the ACS Publications website. 


\section{AUTHOR INFORMATION}

\section{Corresponding Author}

*E-mails: ingo.pinnau@kaust.edu.sa; yanx@stanford.edu

\section{ORCID}

Xiaohua Ma: 0000-0002-1667-6342

Holden W. H. Lai: 0000-0002-0090-9594

Yan Xia: 0000-0002-5298-748X

Ingo Pinnau: 0000-0003-3040-9088

\section{Notes}

A patent application has been filed for the reported polymers and their applications in membrane gas separation.

\section{ACKNOWLEDGEMENTS}

This work was supported by funding (BAS/1/1323-01-01) from King Abdullah University of Science and Technology and the Stanford Natural Gas Initiative. H. W. H. Lai is supported by NSF-GRFP (DGE- 156518).

\section{REFERENCES}

1. McKeown, N. B.; Budd, P. M. Polymers of Intrinsic Microporosity (PIMs): Organic Materials for Membrane Separations, Heterogeneous Catalysis and Hydrogen Storage. Chem. Soc. Rev. 2006, 35, 675-683.

2. $\quad$ Sanders, D. F.; Smith, Z. P.; Guo, R.; Robeson, L. M.; McGrath, J. E.; Paul, D. R.; Freeman, B. D. Energy-Efficient Polymeric Gas Separation Membranes for a Sustainable Future: A Review. Polymer 2013, 54, 4729-4761.

3. Baker, R. W.; Low, B. T. Gas Separation Membrane Materials: A Perspective. Macromolecules 2014, 47, 6999-7013.

4. Koros, W. J.; Zhang, C. Materials for Next-Generation Molecularly Selective Synthetic Membranes. Nat. Mater. 2017, 16, 289.

5. Wang, Y.; Ma, X.; Ghanem, B. S.; Alghunaimi, F.; Pinnau, I.; Han, Y. Polymers of Intrinsic Microporosity for Energy-Intensive Membrane-Based Gas Separations. Mater. Today Nano 2018, 3, 69-95.

6. Low, Z.-X.; Budd, P. M.; McKeown, N. B.; Patterson, D. A. Gas Permeation Properties, Physical Aging, and Its Mitigation in High Free Volume Glassy Polymers. Chem. Rev. 2018, 118, 5871-5911.

7. Corrado, T.; Guo, R. Macromolecular Design Strategies Toward Tailoring Free Volume in Glassy Polymers for High Performance Gas Separation Membranes. Mol. Syst. Des. Eng. 2020. 
8. $\quad$ Ghanem, B. S.; Swaidan, R.; Ma, X.; Litwiller, E.; Pinnau, I. Energy-Efficient Hydrogen Separation by AB-Type Ladder-Polymer Molecular Sieves. Adv. Mater. 2014, 26, 6696-6700. 9. Guiver, M. D.; Lee, Y. M. Polymer Rigidity Improves Microporous Membranes. Science 2013, 339, 284-285.

10. Kim, S.; Lee, Y. M. Rigid and Microporous Polymers for Gas Separation Membranes. Prog. Polym. Sci. 2015, 43, 1-32.

11. Swaidan, R.; Ghanem, B.; Litwiller, E.; Pinnau, I. Physical Aging, Plasticization and Their Effects on Gas Permeation in "Rigid" Polymers of Intrinsic Microporosity. Macromolecules 2015, 48, 6553-6561.

12. Budd, P. M.; Msayib, K. J.; Tattershall, C. E.; Ghanem, B. S.; Reynolds, K. J.; McKeown, N. B.; Fritsch, D. Gas Separation Membranes from Polymers of Intrinsic Microporosity. J. Membr. Sci. 2005, 251, 263-269.

13. Bezzu, C. G.; Carta, M.; Tonkins, A.; Jansen, J. C.; Bernardo, P.; Bazzarelli, F.; McKeown, N. B. A Spirobifluorene-Based Polymer of Intrinsic Microporosity with Improved Performance for Gas Separation. Adv. Mater. 2012, 24, 5930-5933.

14. Carta, M.; Malpass-Evans, R.; Croad, M.; Rogan, Y.; Jansen, J. C.; Bernardo, P.; Bazzarelli, F.; McKeown, N. B. An Efficient Polymer Molecular Sieve for Membrane Gas Separations. Science 2013, 339, 303-307.

15. Carta, M.; Croad, M.; Malpass-Evans, R.; Jansen, J. C.; Bernardo, P.; Clarizia, G.; Friess, K.; Lanč, M.; McKeown, N. B. Triptycene Induced Enhancement of Membrane Gas Selectivity for Microporous Tröger's Base Polymers. Adv. Mater. 2014, 26, 3526-3531.

16. Rose, I.; Bezzu, C. G.; Carta, M.; Comesaña-Gándara, B.; Lasseuguette, E.; Ferrari, M. C.; Bernardo, P.; Clarizia, G.; Fuoco, A.; Jansen, J. C.; Hart, Kyle E.; Liyana-Arachchi, T. P.; Colina, C. M.; McKeown, N. B. Polymer Ultrapermeability from the Inefficient Packing of 2D Chains. Nat. Mater. 2017, 16, 932.

17. Luo, S.; Zhang, Q.; Zhu, L.; Lin, H.; Kazanowska, B. A.; Doherty, C. M.; Hill, A. J.; Gao, P.; Guo, R. Highly Selective and Permeable Microporous Polymer Membranes for Hydrogen Purification and $\mathrm{CO}_{2}$ Removal from Natural Gas. Chem. Mater. 2018, 30, 5322-5332. 18. He, Y.; Benedetti, F. M.; Lin, S.; Liu, C.; Zhao, Y.; Ye, H.-Z.; Van Voorhis, T.; De Angelis, M. G.; Swager, T. M.; Smith, Z. P. Polymers with Side Chain Porosity for Ultrapermeable and Plasticization Resistant Materials for Gas Separations. Adv. Mater. 2019, $31,1807871$.

19. Swaidan, R.; Ghanem, B.; Pinnau, I. Fine-Tuned Intrinsically Ultramicroporous Polymers Redefine the Permeability/Selectivity Upper Bounds of Membrane-Based Air and Hydrogen Separations. ACS Macro Lett. 2015, 4, 947-951.

20. Comesaña-Gándara, B.; Chen, J.; Bezzu, C. G.; Carta, M.; Rose, I.; Ferrari, M.-C.; Esposito, E.; Fuoco, A.; Jansen, J. C.; McKeown, N. B. Redefining the Robeson Upper Bounds for $\mathrm{CO}_{2} / \mathrm{CH}_{4}$ and $\mathrm{CO}_{2} / \mathrm{N}_{2}$ Separations Using a Series of Ultrapermeable Benzotriptycene-Based Polymers of Intrinsic Microporosity. Energy Environ. Sci. 2019, 12, 2733-2740.

21. Budd, P. M.; Elabas, E. S.; Ghanem, B. S.; Makhseed, S.; McKeown, N. B.; Msayib, K. J.; Tattershall, C. E.; Wang, D. Solution-Processed, Organophilic Membrane Derived from a Polymer of Intrinsic Microporosity. Adv. Mater. 2004, 16, 456-459.

22. Budd, P. M.; Ghanem, B. S.; Makhseed, S.; McKeown, N. B.; Msayib, K. J.; Tattershall, C. E. Polymers of Intrinsic Microporosity (PIMs): Robust, Solution-Processable, Organic Nanoporous Materials. Chem. Commun. 2004, 230-231.

23. Carta, M.; Malpass-Evans, R.; Croad, M.; Rogan, Y.; Lee, M.; Rose, I.; McKeown, N. B. The Synthesis of Microporous Polymers Using Tröger's Base Formation. Polym. Chem. 2014, 5, 5267-5272.

24. Rose, I.; Carta, M.; Malpass-Evans, R.; Ferrari, M.-C.; Bernardo, P.; Clarizia, G.; Jansen, J. C.; McKeown, N. B. Highly Permeable Benzotriptycene-Based Polymer of Intrinsic Microporosity. ACS Macro Lett. 2015, 4, 912-915. 
25. Williams, R.; Burt, L. A.; Esposito, E.; Jansen, J. C.; Tocci, E.; Rizzuto, C.; Lanč, M.; Carta, M.; McKeown, N. B. A Highly Rigid and Gas Selective Methanopentacene-based Polymer of Intrinsic Microporosity Derived from Tröger's Base Polymerization. J. Mater. Chem. A 2018, 6, 5661-5667.

26. Wang, Z.; Wang, D.; Zhang, F.; Jin, J. Tröger's Base-Based Microporous Polyimide Membranes for High-Performance Gas Separation. ACS Macro Lett. 2014, 3, 597-601.

27. Zhuang, Y.; Seong, J.G.; Do, Y.S.; Jo, H.J.; Cui, Z.; Lee, J.; Lee, Y.M.; Guiver, M.D. Intrinsically Microporous Soluble Polyimides Incorporating Tröger's Base for Membrane Gas Separation, Macromolecules 2014, 47, 3254-3262.

28. Seong, J.G.; Zhuang, Y.; Kim, S.; Do, Y. S.; Lee, W. H.; Guiver, M. D.; Lee, Y. M. Effect of Methanol Treatment on Gas Sorption and Transport Behavior of Intrinsically Microporous Polyimide Membranes Incorporating Tröger's Base. J. Membr. Sci. 2015, 480, 104-114.

29. Zhuang, Y.; Seong, J. G.; Do, Y. S.; Lee, W. H.; Lee, M. J.; Guiver, M. D.; Lee, Y. M. High-Strength, Soluble Polyimide Membranes Incorporating Tröger's Base for Gas Separation. J. Membr. Sci. 2016, 504, 55-65.

30. Lee, M.; Bezzu, C. G.; Carta, M.; Bernardo, P.; Clarizia, G.; Jansen, J. C.; McKeown, N. B. Enhancing the Gas Permeability of Tröger's Base Derived Polyimides of Intrinsic Microporosity. Macromolecules 2016, 49, 4147-4154.

31. Ghanem, B.; Alaslai, N.; Miao, X.; Pinnau, I. Novel 6FDA-Based Polyimides Derived from Sterically Hindered Tröger's Base Diamines: Synthesis and Gas Permeation Properties. Polymer 2016, 96, 13-19.

32. Liu, S.; Jin, Z.; Teo, Y. C.; Xia, Y. Efficient Synthesis of Rigid Ladder Polymers via Palladium Catalyzed Annulation. J. Am. Chem. Soc. 2014, 136, 17434-17437.

33. Lai, H. W. H.; Teo, Y. C.; Xia, Y. Functionalized Rigid Ladder Polymers from Catalytic Arene-Norbornene Annulation Polymerization. ACS Macro Lett. 2017, 6, 1357-1361.

34. Lai, H. W. H.; Liu, S.; Xia, Y. Norbornyl Benzocyclobutene Ladder Polymers: Conformation and Microporosity. J. Polym. Sci. A Polym. Chem. 2017, 55, 3075-3081.

35. Teo, Y. C.; Lai, H. W. H.; Xia, Y. Arm-Degradable Star Polymers with Crosslinked Ladder-Motif Cores as a Route to Soluble Microporous Nanoparticles. Polym. Chem. 2020, 11, 265-269.

36. Lai, H. W. H.; Benedetti, F. M.; Jin, Z.; Teo, Y. C.; Wu, A. X.; Angelis, M. G. D.; Smith, Z. P.; Xia, Y. Tuning the Molecular Weights, Chain Packing, and Gas-Transport Properties of CANAL Ladder Polymers by Short Alkyl Substitutions. Macromolecules 2019, 52, 6294-6302. 37. Du, N.; Song, J.; Robertson, G. P.; Pinnau, I.; Guiver, M. D. Linear High Molecular Weight Ladder Polymer via Fast Polycondensation of 5,5',6,6'-Tetrahydroxy-3,3,3',3'tetramethylspirobisindane with 1,4-Dicyanotetrafluorobenzene. Macromol. Rapid Commun. 2008, 29, 783-788.

38. Song, J.; Du, N.; Dai, Y.; Robertson, G. P.; Guiver, M. D.; Thomas, S.; Pinnau, I. Linear High Molecular Weight Ladder Polymers by Optimized Polycondensation of Tetrahydroxytetramethylspirobisindane and 1,4-Dicyanotetrafluorobenzene. Macromolecules 2008, 41, 7411-7417.

39. Polak-Kraśna, K.; Dawson, R.; Holyfield, L. T.; Bowen, C. R.; Burrows, A. D.; Mays, T. J. Mechanical Characterisation of Polymer of Intrinsic Microporosity PIM-1 for Hydrogen Storage Applications. J. Mater. Sci. 2017, 52, 3862-3875.

40. Seaton, N. A.; Walton, J. P. R. B.; Quirke, N. A New Analysis Method for the Determination of the Pore Size Distribution of Porous Carbons from Nitrogen Adsorption Measurements. Carbon 1989, 27, 853-861.

41. Ma, X.; Pinnau, I. Effect of Film Thickness and Physical Aging on "Intrinsic" Gas Permeation Properties of Microporous Ethanoanthracene-Based Polyimides. Macromolecules 2018, 51, 1069-1076. 
42. Murali, R. S.; Sankarshana, T.; Sridhar, S. Air Separation by Polymer-Based Membrane Technology. Sep. Purif. Rev. 2013, 42, 130-186.

43. Frisch, H. L. The Time Lag in Diffusion. J. Phys. Chem. 1957, 61, 93-95.

44. Robeson, L. M. Correlation of Separation Factor versus Permeability for Polymeric Membranes. J. Membr. Sci. 1991, 62, 165-185.

45. Robeson, L. M. The Upper Bound Revisited. J. Membr. Sci. 2008, 320, 390-400. 
For Table of Contents Use Only

Facile Synthesis and Study of Microporous CANAL-Tröger's Base Ladder Polymers for Membrane Air Separation

Xiaohua Ma, Holden W. H. Lai, Yingge Wang, Abdulrahaman Alhazmi, Yan Xia,* Ingo Pinnau*

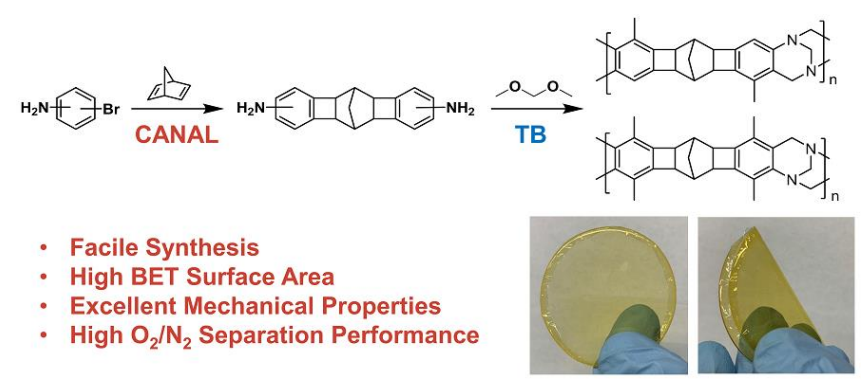

